\title{
Cardiac and renal failure in a 38-year-old alcoholic
}

\author{
Sanjay Sinha, Michael S Norell, Bir S Nanda
}

\section{Case history}

A 38-year-old man presented with anorexia and weight loss over two to three months accompanied by a four-week history of cough, increasing breathlessness, and nausea and vomiting. He smoked 20 cigarettes per day and had a history of alcohol abuse. On examination, his blood pressure was $90 / 60 \mathrm{mmHg}$ and the jugular venous pressure was elevated. He was tachypnoeic with basal crepitations in both lungs. No other general or neurological abnormalities were detected.

The electrocardiogram showed a sinus tachycardia but was otherwise normal. His chest X-ray is shown in the figure. Full blood count, and urea and electrolyte levels were normal, except for a sodium concentration of $125 \mathrm{mmol} / \mathrm{l}$.

Over the next two days he deteriorated rapidly with progressive cardiac failure, hypotension and oliguria. Echocardiogram revealed normal left ventricular dimensions and increased fractional shortening. The haemodynamic data and results of arterial blood gas analysis are given in the table. He was treated with intravenous diuretics, inotropes, bicarbonate, broad spectrum antibiotics, and positive pressure ventilation. There was little improvement in his pulmonary oedema and his renal function continued to deteriorate (blood urea $25 \mathrm{mmol} / \mathrm{l}$, serum creatinine $256 \mu \mathrm{mol} / \mathrm{l})$, leading to anuria and requiring haemofiltration.

Table Haemodynamic and arterial blood gas data (on air)

Arterial blood pressure (mmHg)

Right atrial pressure ( $\mathrm{mmHg}$ )

Right ventricular pressure $(\mathrm{mmHg})$

Pulmonary artery pressure $(\mathrm{mmHg})$

Pulmonary capillary wedge pressure $(\mathrm{mmHg})$

Cardiac output (1/min)

Cardiac index $\left(1 / \mathrm{min} / \mathrm{m}^{2}\right)$

Systemic vascular resistance

Pulmonary vascular resistance

$\mathrm{pH}$

$\mathrm{pCO}_{2}(\mathrm{kPa})$

$\mathrm{pO}_{2}(\mathrm{kPa})$

Bicarbonate (mmol/l)

Base excess

\section{$64 / 42$}

12

$38 / 15$

$50 / 20$

20

8.4

4.8

352 (normal 700-1600)

95 (normal 20-130)

7.29

1.4

10.1

11

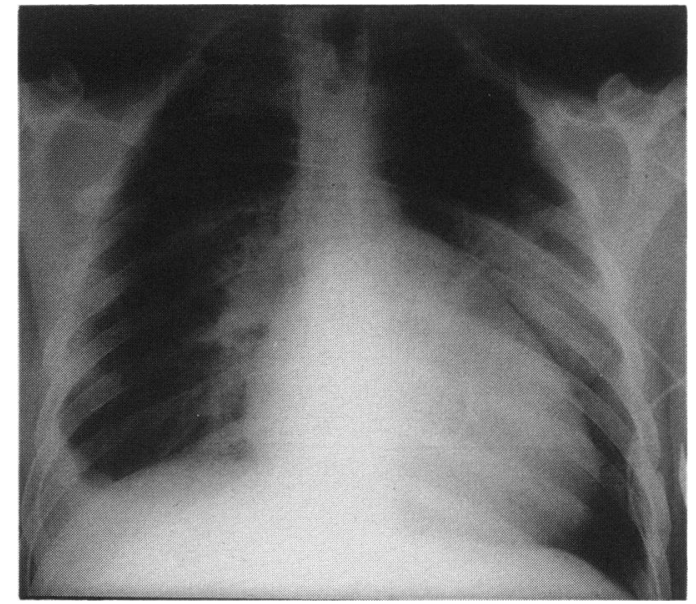

Figure

Castle Hill Hospital,

Cottingham, North

Humberside, UK

S Sinha

MS Norell

BS Nanda

Correspondence to

Dr S Sinha, Research

Registrar, Department of

Cardiology, Wythenshawe

Hospital, Manchester

M23 9LT, UK

Accepted 19 January 1995

\section{Questions}

1 What do the haemodynamic and arterial gas data show?

2 What is the most likely diagnosis? Suggest two other possible diagnoses that need to be excluded.

3 What further treatment is required?

4 Explain the pathogenesis of the arterial gas and haemodynamic abnormalities seen. 


\section{Answers}

\section{QUESTION 1}

The haemodynamic data demonstrate a high output cardiac state with low peripheral vascular resistance. Arterial blood gases reveal a metabolic acidosis.

\section{QUESTION 2}

Beriberi. Septic shock and thyrotoxicosis are two other conditions that need to be excluded. Alcoholic cardiomyopathy may present in a similar way but is ruled out by the echocardiographic and haemodynamic findings.

\section{QUESTION 3}

Immediate treatment with parenteral thiamine (vitamin $B_{1}$ ) is indicated. In the case presented, haemodynamic improvement was seen within 24 hours of receiving this treatment and full cardiovascular and renal recovery occurred within two weeks.

\section{QUESTION 4}

Thiamine is a co-factor at several steps in carbohydrate metabolism. Chronic deficiency leads to accumulation of pyruvate and lactate resulting in a metabolic acidosis. Regional perfusion defects also exist in beriberi ${ }^{1}$ and may result in tissue hypoxia and renal dysfunction, thereby exacerbating the acidosis. This may play a part in producing the marked peripheral vasodilatation and resultant increase in cardiac output that is characteristic of this condition. Hypotension and cardiovascular collapse may be seen in severe cases. It is not yet clear whether there is a specific myocardial lesion

1 Blackett RB, Palmer AJ. Haemodynamic studies in high output beriberi. Br Heart $\mathcal{f}$ 1960; 22: 483-501.

2 Akbarian M, Yankopoulos NA, Abelman WH. Haemodynamic studies in beriberi heart disease. $A m \mathcal{F} M e d$ 1966; 41: 197-212.

3 Attas M, Hanley HG, Stultz D, Jones MR, McAllister RG. Fulminant beriberi heart disease with lactic acidosis presentation of a case with evaluation of left ventricular function and review of pathophysiologic mechanisms. Circulation 1978; 58: $566-72$. secondary to thiamine deficiency as many of these patients have co-existing alcoholic cardiomyopathy.

\section{Discussion}

Cardiac beriberi is caused by chronic, severe, thiamine deficiency and characterised by peripheral oedema, arteriolar vasodilatation, and a high output cardiac state. There may be resultant cardiac failure. ${ }^{2}$ Shoshin beriberi is the fulminating form of this condition with hypotension, low systemic resistance, and metabolic acidosis. ${ }^{3}$ Without prompt and correct treatment this disease can be rapidly fatal. Cardiac beriberi and particularly the shoshin type usually occur in the Far East and Africa and are now rare in the West, although occasionally still seen in alcoholics. Other manifestations of thiamine deficiency - Wernicke's syndrome and peripheral neuropathy may coexist in these patients. ${ }^{4}$ In the past diagnosis was confirmed by measurement of transketolase activity in red cells in vitro before and after addition of thiamine. In the case presented, the diagnosis was verified by direct measurement of thiamine levels in blood using high performance liquid chromatography. ${ }^{5}$ This method is now commonly used and is replacing the transketolase activity assay due to its greatly increased reliability and sensitivity.

\section{Final diagnosis}

Shoshin beriberi with acute renal failure.

Keywords: Shoshin, beriberi, renal failure

4 Wilson JD. Vitamin deficiency and excess. In: Wilson JD et al, eds. Harrison's principles of internal medicine. 12th edn. New York: McGraw-Hill, 1991; pp 436-7.

5 Warnock LG. The measurement of erythrocyte thiamine pyrophosphate by high performance liquid chromatography. Anal Biochem 1982; 126: 394-7. 